
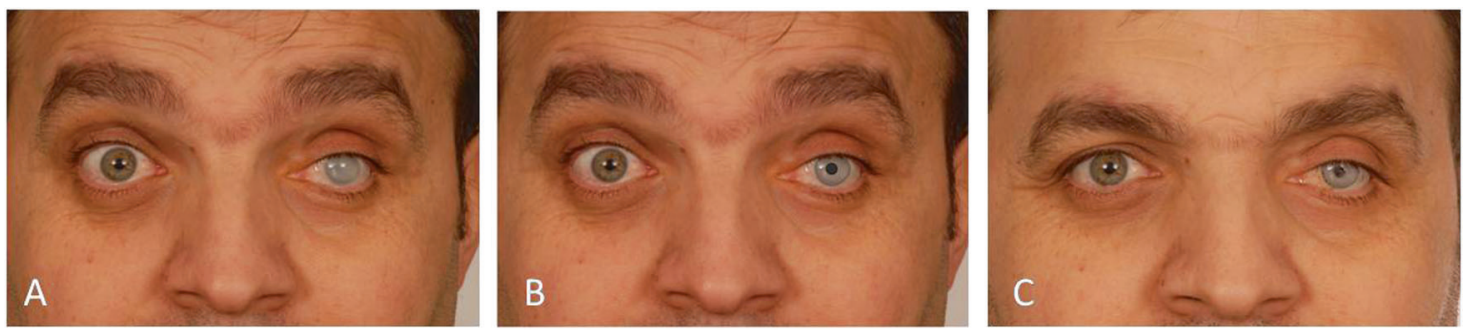

Fig. 1 Preoperative photograph (a) showing the opaque left cornea. Photo editing of the photograph simulated the post-operative appearance (b). The actual appearance 6 weeks after surgery (c) was similar to the simulation

\section{Compliance with ethical standards}

Conflict of interest The authors declare that they have no conflict of interest.

Publisher's note: Springer Nature remains neutral with regard to jurisdictional claims in published maps and institutional affiliations.

\section{References}

1. Pitz S, et al. Corneal tattooing: an alternative treatment for disfiguring corneal scars. Br J Ophthalmol. 2003;86:397-9.

2. Khan AO, Meyer D. Corneal tattooing for the treatment of debilitating glare in a child with traumatic iris loss. Am Journal of Ophthalmol. 2005;139:920-1.

3. Kandinov A, et al. Analysis of factors associated with rhytidectomy malpractice litigation cases. JAMA Facial Plast Surg. 2017;19: 255-9.

\title{
How stressful is cataract surgery for consultants and ophthalmic trainees? Phacoemulsification is a stressful experience for young consultants
}

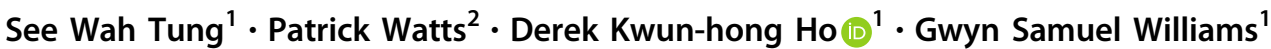

Received: 24 September 2018 / Revised: 5 March 2019 / Accepted: 8 March 2019 / Published online: 1 April 2019

(c) The Royal College of Ophthalmologists 2019

\section{Introduction}

It has long been recognized that intraoperative stress is worse for inexperienced cataract surgeons [1]. Sleep quality is thought to be a big factor in determining stress levels

See Wah Tung

annieswtung@ doctors.org.uk

$\triangle$ Gwyn Samuel Williams gwynwilliams@doctors.org.uk

1 Department of Ophthalmology, Singleton Hospital, Sketty Lane, Swansea SA2 8QA, UK

2 Department of Ophthalmology, University Hospital of Wales, Heath Park Way, Cardiff CF14 4XW, UK during surgical procedures, with poor sleep being a big contributor [2]. Stress is associated with underperformance which can affect the functioning of an entire surgical unit [3]. It is therefore vital to understand the often underreported prevalence of stress amongst trainee and consultant cataract surgeons, and to this end we circulated an online survey to every ophthalmic trainee and consultant ophthalmic surgeon in Wales to determine the levels of stress experienced as a direct result of cataract surgery.

\section{Methods}

The Maslach Burnout Inventory (MBI) is a well respected study for assessing stress and burnout [4]. Section A of this questionnaire deals specifically with stress and consists of 
seven questions, which were slightly modified to suit cataract surgery. The MBI grades burnout through stress on a scale from 0 to 42 with scores of 18-29 representing moderate burnout and scores of greater than 29 representing severe burnout. The trainees were also asked how many cataracts they had performed, as well as their year of training, while consultants were asked how many years they had been practising and how stressful they found supervising trainees. The Survey Monkey tool was used to undertake this assessment.

\section{Results}

Of the 29 current Welsh ophthalmic trainees 26 completed the survey, while 40 of the 57 consultants did, though one of these responses was invalidated. The trainees demonstrated stress levels of $0-10$ on the MBI with an average score of 5.8. This demonstrates a surprising finding of very low levels of stress amongst trainee cataract surgeons. Consultants as a group demonstrated stress levels of 0-23 on the MBI with an average score of 6.9. Six demonstrated scores of 18-23 which correlates with significant burnout. When the consultant body is broken down into groups by years of experience those with less than 5 years experience $(n=15)$ demonstrate an average stress level of 10.7 with five of the six of those being in the moderate stress category being in this group. The average for consultants of more than 10 years experience $(n=13)$ was 4.2 , demonstrating levels of stress lower even that the trainees.

Consultants were asked how often they experienced stress while supervising trainees and of the 39 valid responses only one stated they never experienced stress $(2.5 \%)$.

\section{Discussion}

It is surprising that trainee cataract surgeons, despite papers demonstrating a direct correlation between inexperience and increased stress [1-3], admit to universal low levels of stress during cataract surgery. It is also interesting how inexperienced consultants admit to on average more stress than any other group and contain 5 of the 6 total respondents who fall under the "moderate burnout" of the MBI tool. This suggests that while cataract training in Wales seems to be robust at protecting trainees from significant stress, new consultants seem to be affected by burnout more than any other group. Perhaps additional support may help with this.

\section{Compliance with ethical standards}

Conflict of interest The authors declare that they have no conflict of interest.

Publisher's note: Springer Nature remains neutral with regard to jurisdictional claims in published maps and institutional affiliations.

\section{References}

1. Yamamoto A, Hara T, Kikuchi K, Hara T, Fujiwara T. Intraoperative stress experienced by surgeons and assistants. Ophthalmic Surg Lasers. 1999;30:27-30.

2. Andersen LP, Klein M, Gogenur I, Rosenberg J. Psychological and physical stress among experienced and inexperienced surgeons during laparascopic cholecystectomy. Surg Laparosc Endosc Percutan Tech. 2012;22:73-78.

3. Rashid P, Grills R, Kuan M, Klein D. Trainee underperformance: a guide to achieving resolution. ANZ J Surg. 2015;85:303-7.

4. Pisanti R, Lombardo C, Lucidi F, Violani C, Lazzari D. Psychmetric properties of the Maslach Burnout Inventory for human services among Italian nurses: a test of alternative models. J Adv Nurs. 2013;69:697-707. 